\title{
Sociocultural-Interdeterminist Dialogical Perspective of Intercultural Mutual Understanding Comprehension Deepening
}

\author{
Vladimir Yanchuk \\ Department of Psychology, Belarus State University, Minsk, Belarus \\ Email: yanchuk1303@gmail.com
}

Received August 2014

\section{Abstract}

Sociocultural-interdeterminist dialogical approach focuses attention on the caused interdeteministic character of mutual relations of situational, personal and activity determinants of the behaviour, staticized in concrete historical cultural context. For example, a change in a situational context leads to changes both in the person, and in his or her activity. Achievement of changes in the person and his or her activity assumes creation of the special conditions promoting to their actualization, etc. For understanding of the nature of progress in culture and science the theoretical construct "cultural-scientific tradition" is offered, allowing to trace changes in common cultural and scientific worldview throughout the human history. Consideration of personality problems is carried out in a three-dimensional continuum conscious-unconscious-existential, allowing to capture all variety of displays of psychological phenomenology. Proceeding from understanding of culture as orientational and normative structure of behaviour and as communicative matrix by means of which the behaviour is interpreted, integrated, coordinated and authorized (R. Priest), efficiency of use of the conceptual device of the epistemic approach of Michel Foucault and cultural framing of E. Goffman to understanding of intercultural interaction specificity is proved. The epistemic differences of European (graphic), Chinese, and classic Arabic languages are demonstrated. Intercultural competence is considered in aspect of ability of formation of shared meanings and experiences on the basis of mastering by knowledge about originalities of language, values and norms, experiences and behavioral algorithms of each other. The basis of such mutual understanding creates the dialogue that assumes unconditional acceptance of another based on tolerance and pluralism, the joint extension of the horizons directed on formation and development of coordinated and mutually endured values and senses. As unit of the analysis of intercultural interaction the evaluation of a sharedness of meanings and experiences is offered. Results of empirical research of the given approach on the example of formation of interpersonal mutual understanding of the Belarus and Chinese students are presented.

\section{Keywords}

Cultural Competence, Cultural Framing, Culture, Cross-Cultural Comparison, Dialog, Ecocultural Dialogical Educational Environment, Episteme, Epistemology, Emic, Ethic, Framing, Interdetermination, Integration, Intgrative-Eclectic Approach, Integrative Eclectic through Triangulation, Intersubjectivity, Intertextuality, Mutual Understanding, Shared Meaning, 


\section{Sociocultural-Interdeterminist Dialogical Approach}

\section{Introduction}

Consideration of theoretical aspects of the problem of cultural competence formation in intercultural interaction gets new foreshortenings in connection with the numerous transformations occurring as in a historical and cultural context, and psychological knowledge as that. The scientific orientation on integration of interparadigm and interdisciplinary researches of problems of the social-psychological nature of the personality development, group, a society, necessary for the complex decision of problems of a modern psychological science, assumes a reflection of the present for adequate self-determination in the future. It should promote development of the interdisciplinary integrative tendencies peculiar to modern knowledge, carrying general methodological character and being accompanied by the practical demonstrations supported with results of empirical researches.

For understanding of the nature of progress in culture and a science in whole and in social psychology in particular, run backing of changes in common cultural and scientific worldview throughout a human history is useful. For this type analysis realisation we offer the theoretical construct "cultural-scientific tradition”, allowed to reveal and articulate efficiency of the postmodernist polyphony leading to expansion of horizons of vision of problems and the dialogical coordination of their decisions [1]. Characteristic for the present stage of psychological knowledge development integrative tendencies demand not simply ascertaining, and offers of the mechanisms, one of which possible variants offer author's integrative-eclectic approach to the analysis of psychological phenomenology and its development in the general methodological sociocultural-interdeterminist dialogical approach. In the first case it is a question of a finding of the bases for interparadigm dialogue as a mechanism of cultural and psychological phenomenology understanding deepening, and in the second about the relation of an interdetermination of personal, situational and activities determinants of the behaviour, placed in a historical-cultural context of development.

Consideration of social psychology problems is carried out in a three-dimensional continuum consciousnessunconsciousness-existential dimension of the self, allowing capturing all variety of psychological phenomenology manifestations.

The modern line of an original reminiscence since L.S. Vygotsky cultural historical approach the concept "culture” in a psychological science assumes reconsideration of its maintenance taking into account achievements in various areas of knowledge (anthropology, philosophy, linguistics, sociology, etc.) Taking into account one more sign tendency_multidisciplinary integration of knowledge about human nature. Proceeding from understanding of culture as an orientational and normative framework for behavior, and as a communicational matrix through which behavior is interpreted, integrated, coordinated, and sanctioned (R. Priest), efficiency of use of the conceptual device of the epistemic approach of Michel Foucault and cultural framing approach of Irving Goffman for understanding of specificity of intercultural interaction and mutual understanding is proved. In a language context as system basis of culture, epistemic distinctions European (graphic), Chinese (hieroglyphic) and classical Arabian the languages, shown available expressed cultural distinctions in interpretation and world experience are shown. Grasping of these distinctions are defined by generatedness of interpersonal interaction participant's cultural and intercultural competence. Intercultural competence is considered in aspect of ability of divided values and experiences formation based on mastering by knowledge about originalities of language, values and norms, experiences and behavioral algorithms each other. The basis of such mutual understanding creates the dialogue assuming based on tolerance and pluralism, unconditional acceptance of another, the joint expansion of the horizons directed on formation and development of coordinated and in common endured values and senses. As unit of the intercultural interaction analysis offered estimation of a coordination of values and sharedness of meanings. It causes promotion as unit of the analysis of divided values and the shared meanings defining authenticity of interpretations and experiences of an event. Presence of such in common developed units of the analysis, providing qualitative improvement of an ecological validity, puts a problem of a finding of optimum combinations of qualitative and quantitative methods of studying of the psychological phenomenology, found the expression in various variations of a methodological triangulation and, in particular, its author's version of integrative eclecticism by triangulation.

Construction of mutually developed shared meanings, values, norms, the coordinated activities creates pre- 
conditions for a finding of new resources of a problem of interpersonal mutual understanding and a mutual experience vision as process and result of the interpersonal interaction providing infinity of development of mutual relations. The characteristic of the eco-cultural dialogical developing educational environment as conditions of formation of intercultural competence is given

\section{Sociocultural-Interdeterminist Dialogical Perspective of Intercultural Mutual Understanding Deepening}

Analyzing a problem of intercultural mutual understanding comprehension deepening, it is necessary to ascertain necessity and utility of the reference to the achievements, which have been saved up in different systems of paradigm coordinates, traditions and directions of psychological knowledge. Throughout a number of years, the author proved idea of interparadigm dialogue as resource of psychological knowledge development and deepening [1]-[4]. The problem of interparadigm and interdisciplinary dialogue is a point of issue of psychological community any more one ten years, showing the broadest spectrum of author's positions and approaches and, simultaneously, extreme deficiency of constructive offers. In essence, the modern psychological knowledge represents, as mark Yanchar and Slife, "a dizzying array of irreconcilable theories, models, methods, and even philosophies" [5], which marthe discipline's credibility and progress. Further, they note that the problem dates back to psychology's modern inception and derives ultimately from the deep-seated, and perhaps ineradicable, philosophical tensions that pervade it. Goertzen [6] supports a similar assessment, and vigorously contends that the persistence of fragmentation constitutes a disciplinary "crisis" in urgent need of resolution. Since the status of the problem clearly has implications for how it is responded to, let me consider why a more moderate evaluation might be warranted.

Such searches were especially actualized by end of XX century in connection with strengthening of positions of the postmodernist cultural-scientific tradition proclaiming a celebration of variety as a resource of an exit from modernist deadlock in scientific knowledge development, in detail presented in the accented publications [1] [4] [7]. In any textbook on personality psychology, theories of the personality constructive sections representing alternative paradigm approaches have started to appear. In serious scientific periodicals, such, as, for example, "Culture and Psychology", "Current Directions in Psychological Science”, "Integrative Psychological and Behavioral Science", "New Ideas in Psychology", "Perspectives on Psychological Science”, "Philosophical Psychology", "Theory and Psychology", etc. the fundamental articles analyzing psychological phenomenology through a prism of alternative positions and sights, with accent on revealing of the bases and ways of interparadigm dialogue have started to be published [6] [8]-[11]. This circumstance, as well as attempts of search of answers to sacramental questions: why there are many psychologies? Moreover, why they do not unite in is unique true and comprehensive? - has predetermined a main objective of given article. It consists in the offer of the constructive decisions directed on integration psychologist's efforts, representing various paradigms, traditions and approaches, in a finding of a psychological science and practice development additional resources and of psychological phenomenology understanding deepening.

All bases on which it is possible to take of any methodological position, finally, appear derivative of world outlook installations by which the researcher or an expert is guided. And how various applicants for a substantiation of the bases of "cleanliness of scientific knowledge" tried to give reason for criteria of "objective knowledge», all of them face numerous counterarguments of the opponents shooting at them "an Achilles' heel": the inevitable author's subjectivity caused by own preferences, individual or collective experience of the concrete scientific community which have occupied, due to various reasons, including ideological, political, the predominating position in concrete area of knowledge and point of space and time. However, time changes, the worldview including scientific that has been excellent shown T. Kuhn in his famous analysis of a science development on an example of scientific revolutions changes also. The scientific worldview changes including in a revolutionary way, considerably transforming it would seem firm postulates.

Changes in scientific worldview make direct impact and on worldview change as a whole. The concept worldview last years becomes in the center of attention of the researchers working in the field of culture and intercultural mutual understanding. Its importance is conditioned that cultural worldview answers ultimate questions about humanity and the universe — the triworld of humans, nature, and the supernatural [12] —and their relationships (e.g., Who are we? Where have we been before birth? Where will we go after death? For what do we live? What should we do in this secular world? How should we relate to other humans, nature, and the spirits?). 
Samovar, Porter, and McDaniel [13] define a worldview as "a culture’s orientation toward God, humanity, nature, the universe, life, death, sickness, and other philosophical issues concerning existence” [14]. A worldview should be regarded [as] neither completely static nor completely fluid. It is always evolving and transforming and yet maintains the contours of the culture. Different portions of the worldview are instilled in the minds of different members of the culture [15].

It is obvious that the worldview changes in time and should influence on interpretation of cultural phenomenology and intercultural mutual understanding in particular. The understanding of worldview evolution in historical prospect has demanded working out of the special construct "cultural-scientific tradition", representing polysemantic and dynamically flexible depending on a historical, social and national context complex of philosophical, epistemological, scientific-theoretical and emotionally-aesthetic representations ... the characteristic of the certain mentality, a specific way of world perception and interpretation, world experience and an estimation both cognitive possibilities of the person, and its place and a role in world around [7]. Introduced construct allowed to track dynamics of the worldview bases of various cultural-scientific traditions (syncretism, cosmocentrism, teocentrism, anthropocentrism, modernism, postmodernism), found the higher embodiment in a postmodernist celebration of variety as propeller of culture and science [1]. It has been convincingly shown, what exactly presence of alternatives including at paradigm level, allows to overcome inevitable for any knowledge constructed on the universal, invariable dogmatic basis of deadlock, its heuristic potential defined by an exhaustness, a bright illustration of that are scientific revolutions.

The concept of culture is central in designated context of analyzed problem area. Detailed consideration of existing variety of approaches to its definition offers Jahoda [21]. He starts analysis from Kroeber and Kluckhohn's [22] classic monograph, which listed some 160 definitions and added their own. For Kroeber \& Kluckhohn definition "Culture consists of patterns, explicit and implicit, of and for behavior acquired and transmitted by symbols, constituting the distinctive achievement of human groups, including their embodiments in artefacts; the essential core of culture consists of traditional (i.e. historically derived and selected) ideas and especially their attached values; culture systems may, on the one hand, be considered as products of action, on the other as conditioning elements of further action" [22]. The following is an analysis of different authors approaches adhering alternative theoretical positions and paradigmatic coordinate for the period from 2009 to 2011 years ending with the conclusion about principal impossibilities of finding exclusively true and necessity "simply to use the term without seeking to define it. However, if either for a theoretical or empirical reason clarification is essential, then the author should explain the specific manner in which she employs the term "culture" in that particular context” [20]. Presented critical reflection has not constructive nature, once again confirming necessity of essentially new theoretical-methodological bases finding considering of modern situation singularity in culture and science, characterizing of diversity and polyphony existence, including multiculturalism.

In my own analysis I'm proceeding from definition of culture introduced by R. Priest as learnt configuration of categories, images, assumptions, beliefs, values, norms, and other symbolic elements widely shared among members of a given society or social group which functions as an orientational and normative framework for behaviour, and as a communicational matrix through which behaviour is interpreted, integrated, coordinated, and sanctioned, which we take as basic at carrying out of own analysis of problem area. In supplement, I will note the productive line of last years formulated in frameworks dynamic constructivist approach to culture of Hong. He proposes to pin down the causal mechanism through which culture exerts its influence and defines culture "as networks of knowledge consisting of learned routines of thinking, feeling, and interacting with other people, as well as a corpus of substantive assertions and ideas about aspects of the world ... it is ... shared ..., among a collection of interconnected individuals who are often demarcated by race, ethnicity, or nationality; (b) externalised by rich symbols, artefacts, social constructions, and social institutions (e.g. cultural icons, advertisements and news media); (c) used to form the common ground for communication among members; (d) transmitted from one generation to the next ...; (e) undergoing continuous modifications ... "[19]. Especially interesting is an intersubjective consensus approach to culture Wan and Chiu. According to this view "culture consists of symbolic elements that members of a culture generally believe to be important to or characteristic of the culture". Authors underline "When people in a culture agree on what symbolic elements are important to the culture, these elements become the core elements of the culture" [20]. In thus giving priority, when defining culture, to people's consensual perceptions of what is important in their culture.

Ishii [21] proposes a three-layer-structure model of culture. According to him, culture consists of three layers -material, behavioral, and mental. The most external, overt, and visible layer of culture is the material one, 
which is represented by various artifacts (e.g., food and clothing) produced, operated, and controlled by the behavioral layer. The semi-overt layer of culture is the behavioral one, which is [composed] of verbal and nonverbal behaviors as symbols (e.g., words and gestures) and reflects the mental layer. The most internal, covert, and invisible layer of culture is the mental one, which functions in the form of values, beliefs, and attitudes. For his opinion "understanding the mental layer is the most important in intercultural communication situations because it is the core of culture which operates and controls the two outer behavioral and material layers" [29].

Ascertaining of a multyparadigmality and multyvoicesness of culture definition puts extremely difficult taskself-determination challenge in it. Complexity of its decision is caused also by traditional propensity of domestic consciousness (and not only) to a finding is unique true and, it is desirable unique decisions. The evidence to that is proceeding opposition of positivistic and constructivist research traditions.

The decision of this not a simple problem also has predetermined working out of the author's integrative-eclectic approach to the analysis of the social and psychological phenomenology, directed on a finding of the bases for interparadigm dialogue. The integrative eclecticism is understood as phenomenon nature comprehension through integration accompanied by critical reflection, eclecticism of various traditions, approaches, logics and tools, at maintenance of their autonomy in the subsequent development [1]. Its essence consists in the multiplane, multidimensional, multivectoral analysis creating possibility of qualitatively other insight, assuming inclusion in a plane of the analysis aspects of plurality, dialogicity, and diatropicity of analyzed phenomenon. Standing in alternate position, inclusion in a competition of ideas, the critical reflection, critical positioning gives possibility of the out-of-body analysis turning to one more «the eternal propeller» of knowledge progress. It is a question not of integration, as inevitably generating tendency to monopoly on the truth with all that it implies, and about free operating by the multifacetness, multivectoral knowledge connected with traditions most productively working in problem area and their toolkit.

The methodological foundations of integrative eclecticism are concepts of multialternativeness of truth, ontological pluralism, dialogic and diatropic. The integrative eclecticism assumes involvement to the analysis the findings and achievements of those traditions, those approaches that most productively work in concrete phenomenal area. The integrative eclecticism offers following mechanisms of psychological knowledge development: paradigm positioning; integrative-eclectic dialogue of alternative traditions; and critical reflective positioning (an alternative circle). These mechanisms are actualized in a number of necessary conditions providing increase of scientific research potential of efficiency enhancement:

- clear-cut definition of paradigm coordinates in which frameworks and the possibilities connected with them and restrictions research is conducted in extrapolation of results;

- creation of the maximum information base of theoretical and empirical elaborateness of problem field in different systems of paradigm coordinates in the presence of such possibilities and claims for high level generalisations;

- passing of a critical reflective circle of alternative positioning as conditions of paradigm frameworks extension and clearing of bias and transition to higher order metatheoretical level.

Interparadigm dialogue that it did not become dialogue for the sake of dialogue, should assume definiteness of the subject, it is desirable, covering the greatest possibilities of researched phenomenology manifestations and descriptions in all constituted paradigms coordinate systems has stood the test of time and possessing highest creative potential. The general object for all psychological paradigms coordinates systems is the person in its interaction with social and natural environment, namely interrelation of internal world inaccessible for direct observation and measurement, with its external manifestations actualized in behaviour, activity, etc. Initially having issued as the doctrine about a spirit (psyche), the psychology in the subsequent was transformed to a science about behaviour, mentality, cognition, etc. General for given psychological constructs is person internal world or overt behavior which manifestations are extremely diverse and versatile. The person lives in the world, endures it, definitely operates, comprehends, and makes decisions. On all of this influences variety of factors: the natural and social environment, life history and many other things. Something from the causal bases occurring with person is conscious, and something unconscious. Anyway this internal underlying reason of outwardly observable behaviour remains mystery inaccessible to objective measurement as for the subject, and the observer that, in aggregate, and creates the bases for the plural interpretation assuming forming of various assumptions and their subsequent verification in practice, resulting in hypotheses confirmation, or to the concrete problems decision.

The finding of psychological phenomenology and phenomenology of intercultural mutual understanding comprehension deepening resources in particular in conditions of existing paradigm and cultural diversity as- 
sumes also working out of the psychology subject definition including the greatest possible quantity of these diversity manifestations. It makes necessary basis for interparadigm dialogue between existing paradigms coordinates field considered as a condition and mechanism of psychological knowledge development. The variant of the given problem decision represents author's psychology subject definition as "being-in-the-world of the Self as bio-psycho-social socioculturally-interdeterminated dialogical essences in interaction with a social and natural environment in consciousness-unconsciousness-existential dimensions" [24]. The category "being-in-theworld" focuses attention on existential aspect of the person life underlining human "enweaveness" in the life, its experience. Ego-involvement defines as event interpretation soon as its experience and reaction sometimes unexpected manner as for outsider and insider. Without empathetical approximation for existential feelings is impossible, evaluate importance of occurrent for the subject his attachment with it. The category "Self" concentrates on the aspect of interconnectedness of the internal and external in personal world manifested in dynamic interrelation of human with its internal and external environment (social, natural), necessary for understanding its behavior in this concrete point of time and space, conditioned by past personal experience, relations with proximate social surroundings, political regime, and so on. There is stressed the important role of ego-extension in the world experience not always been aware by the subject. The three-dimensional bio-psycho-social continuum focused on complexity of interaction of three diverse qualitative natures-biological, psychical and social. Sociocultural interdeterminism underlines aspect of persons, activity and its situational context reciprocal interdetermination, shown that any change in one of them leads to change in two others. At last, the psychological phenomenology is historically analyzed in dimensions of consciousness, unconsciousness and existential.

The designated multidimensional maintenance of psychology subject, from my point of view, also should set frameworks of psychological research, an explanation and understanding of the intercultural mutual understanding phenomenology assuming a finding of coordination, giving relative definiteness (orderliness) in itself and relation to the world. Such qualitative multinatureness demands also the special type of psychological phenomenology explanation assuming, first, initial tolerance, plurality and reflexivity of the researcher consciousness; secondly, processuality; thirdly, sociocultural interdeterminationality and constructiveness; fourthly, coexistence of qualitatively diverse natures; fifthly, existential beingness; at last, sixthly, mechanisms of special type of integration both multiqualitative natures, and the knowledge which has been saved up in alternative traditions and approaches.

The decision of such problem assumes presence and other type of logic-dialogical, putting forward alternatively classical "or/or" dialogical "and/and" at which alternative approaches start to be considered not as mutually exclusive, and as complementary. Development of ways and means of adjustment of the productive interparadigm and interdisciplinary dialogue directed on a mutual enrichment and reciprocal growth in the field of psychological phenomenology understanding deepening becomes the purpose of development of scientific knowledge.

Realisation of dialogical logic "and/and" demands working out of essentially new methodological approach, allowing to create the bases for the original dialogue inherently initially assuming mutual acceptance and development of joint decisions of consensual type. The sociocultural-interdeterminist dialogical addition offering a number of conditions of psychological phenomenology understanding deepening:

- plurality and tolerance inherently, realised in the initial acceptance of the fact of possibility and utility of existence of alternative explanations of the nature of analyzed phenomena;

- coordination initial ontological and epistemological bases defining the relation to the most fundamental questions, connected with cognoscibility of the researched and explained reality accompanied by ascertaining of coincidence and a mismatch of positions;

- sociocultural interdeterminacy expressed in a recognition of interference and interconditionality of all factors, present at process of a studied phenomenon functioning;

- dialogicity, manifested in ability of joint knowledge creation taking into account the individual and cultural distinctions, based on the logic of a mutual enrichment and reciprocal growth.

There is one way to avoid a paradigm-specific focus in psychological theorizing is to search for more integrative accounts of empirical phenomena across different paradigms [25]. Narrow concentration on one paradigm in the theoretical analysis and research can cause rather essential damage to science development. The predictive and explanatory range of a theory should be extended to different paradigms, because testing the implications of a theory across multiple paradigms allows one to provide converging evidence for the underlying concepts and to demonstrate the theory's universality and external validity [26]. In many respects resounding with described 
above, conditions of interparadigm dialogue offers Healy: 1) investigative openness; 2) equal partnership; 3) mutual understanding and potentially transformative learning; 4) critical intersubjectivity and accountability [27]. Sternberg and Grigorenko cite some eight epistemological "reasons to change" centered on the insight that, like the proverbial elephant, psychological phenomena need to be understood from multiple perspectives, not just one [28]. Moreover, they are optimistic that over time recognition of the knowledge fragmentation limitations and the corresponding benefits of an enhanced, collaborative understanding of psychological phenomena will motivate psychologists to adopt a more integrative approach. Example of such integration with reference to personality psychology is author's attempt of integration of the trait theory and worldview approaches A. Nilsson, underlining that "by developing integrative frameworks of abstract personality constructs and generalities that strip away individuality and context, we can thereby, in fact, facilitate the integration of different strands of evidence about personality into idiographic personality portraits, both within psychological studies and everyday life" [29].

Within the framework of the sociocultural-interdeterminist approach author's attempt of transformation of the known Levinian formula of the behaviour description $B=f(P, S)$, describing behaviour as derivative of the person and a situation in a condition of an interdetermination personal, situational and activitistic a determinant of the behaviour, being in a condition of processual interference and the mutual change (Figure 1).

In the interdetermination basis the principle reciprocal determinism [30] according to which personal, activitistic and situational determinants of behaviour are in the relation of interconditionality. The interdetermination principle focuses attention not only on a condition of interdetermination, but also reciprocal growths in a sociocultural context. The classical formula of the description of behaviour $B=f(P, S)$ takes the following form

$$
\left\{\begin{array}{l}
A=f(P, S) C, \\
P=f(A, S) C, \\
S=f(P, A) C,
\end{array}\right.
$$

where $A$ designates activity; $P$-personality; $S$-a situational context; $C$-historical-cultural context.

Any change in a situational context is inevitably reflected both in features of the personality, and on character of its activity and on the contrary. For example caused by a constancy of activity and a situational context professional deformation are expressed in personal deformations, in turn, reflected in perception surrounding and character of interaction with it. As consequence, overcoming of professional deformation with necessity assumes creation of the alternative environment promoting expansion of "vision horizons" surrounding, in turn assuming possession alternative activity, promoting adaptation to the changed environment etc. With reference to a problem of intercultural mutual understanding deepening of comprehension of their nature is a question of necessity of inclusion for a studying plane interdeterministic relations of situational, personal and activitistic components of social behaviour creating possibility as expansion of representations about studied phenomenology, and deepening of its nature understanding.

Realisation of the sociocultural-interdeterminist dialogical approach in methodological aspect assumes clearing of some the connected problem areas: the theoretical argumentation and a research method. There is obvious a limitation of explicitly structured argumentation (based on necessity of empirical acknowledgement of any element of the theory-deduction, induction, retroduction, abduction) and necessity of increase of implicitly

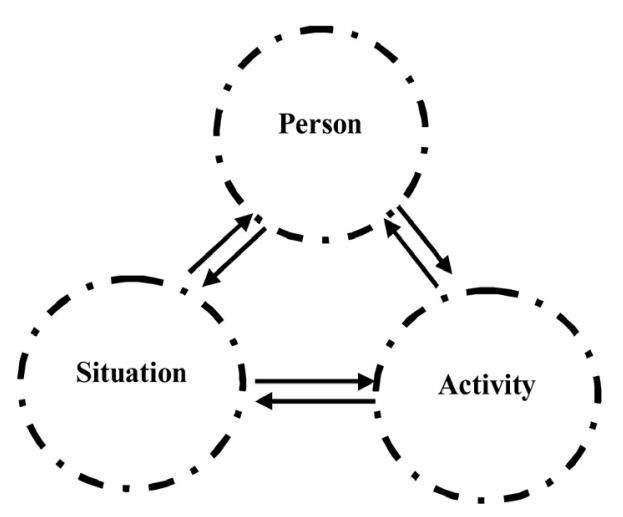

Figure 1. Interdeterminist triangle. 
structured confirmation role (based on smaller dependence on empirical acknowledgement and accentuation on logic sequence and consistency, persuasiveness and acceptances by the interested and qualified reader — descriptive explication, sensitizing, analytical induction) [1] [31].

In the field of research method search of an optimum combination of quantitative and qualitative methods possibilities where carried out. An example of that is the methodological triangulation and its author's modification - integrative eclecticism through triangulation [1]. Realising ideas of dialogue in relation to research methods where offered dialogical methodologies, winning the increasing popularity last years. An example to that is the alternative democratic approach as an interpretativism of the mixed methods [1]. The given approach changes a role of quantitative methods of research, giving them an auxiliary role. The interpretativism of the mixed methods proclaims understanding of the person in its own concepts. It involves interested parties by means of inclusion and dialogue principles. The inclusion principle represents democratic dimension, maintenance how much it is possible, hearings of all participating voices. The dialogue principle establishes necessity of involving of all interested parties and granting of that discussion possibility by it why something occurs and that should occur. Joint critical dialogue assumes of expert knowledge superimposement in consideration of a situation and by means of it achievement of possibility of an exit for limits given at the expense of association of professional possibilities of the researcher and access to an informant reality.

Practical realisation of joint critical dialogue inevitably faces a problem of cultural both paradigm variety as a whole and a framing set by them in particular. Researchers of different cultural traditions, paradigm preferences, schools and approaches are doomed to the variant of studied phenomena caused by distinctions in the epistemological bases, theoretical metaphors and ways of the proof, the conceptual device, research methods, etc. All it predetermines necessity of a finding of the comprehensible methodological bases of the interparadigm dialogue one of which offers author's sociocultural-interdeterminist dialogical approach already represented above to the analysis of psychological phenomenology. A bright example of productive possibilities of realisation of the approach is studying of a problem of cultural variety spent by us in a context of the cultural framing [32]. The revealed features in many respects are similar to self-determination discussed above in paradigm variety. Paradigms co-ordinates also show the original cultural frames causing distinctions in interpretation of psychological phenomenology. These distinctions based on alternative ontological and epistemological the bases, give possibility of studying of psychological phenomenology in different foreshortenings of vision and an explanation, creating conditions for expansion of horizons and understanding deepening.

\section{The Problem of Cultural and Intercultural Competence in Social and Cross-Cultural Psychology}

The worldview analysis is useful for carrying out at the epistemic level, entered into the conceptual device of philosophy Michel Foucault. This term where firstly introduced by Foucault [33] [34] who used it in his analysis of the archeological level of discourse. Foucault defined the episteme as an implicit structure of cultural and historical reason that subjects all branches of knowledge to constitutive norms and postulates. His analysis explored discursive acts "from the point of view of the rules that come into play in the very existence of such discourse" [35]. It is an original discourse, the formation defining a way to which the world is represented or "sees", that cultural matrix setting vision, experience and interpretation of the social and natural world both at individual level, and at level of the community united by given cultural tradition. The principles that compose the episteme obey a governing rational or a group logic, which guides their action. This is similar to Pepper's [36] idea of root metaphors that act as the motivating force for systems of thought. Four distinct rationales are presented which guide the behavior of all principles and which generate four separate types of epistemes. In that sense, if more principles where added to the episteme they would function in a manner according to the same logical guideline. Each episteme presents a distinct form of organizing knowledge. This has obvious consequences for the way of reality understanding, which will be different for each epistemological type of self. The interpretive framework of a certain episteme is not similar to the framework offered by other epistemes. The different kinds of basic epistemes are hence mutually exclusive; understanding the world through lenses supplied by one type of episteme is a whole and absolute experience. It follows that a person can be said to normally possess only one type of an episteme and only one type of a self.

Bukobza [34] describes six categorical principles that compose the epistemes will presently be delineated: consistency-inconsistency, fixedness-dynamism, form preservability-transformation, singularity-plurality, con- 
text independent-context dependent, other independent-other dependent. Each principle can be applied in four different ways according to the four basic governing rationales. For analytical reasons the two poles of each principle will presently be exhibited, and later they will be further elaborated in terms of the four types of epistemes. For the same reason the principles are distinguished from one another and discussed separately, though within the actual episteme they exist and function in a collaborative and interactive manner. The four fundamental epistemes were named monolithic-monoformal (MM), relative-relational (RR), dialectic-deconstructive (DD), and integral-inclusive (II). They will presently be delineated, with reference first to the assumption of their guiding rationale and then to each of the aforementioned principles.

Variety of the Self-researches in various cultures shows their variative character. If the western researches describe Self as defined principles of continuity, stability, the uniformity, in corresponding MM to episteme southeast cultures are described RR by the episteme considering it as possessing rather nontight borders, susceptible to changes and social contexts. Such Self structure is differentiated and includes independent parts. Embodiments DD and II epistemes are less studied. As acknowledgement of this predeterminatedness the researches spent in neurosciences, showing essential cultural distinctions at level of brain activity, and at morphological level act also numerous empirical cross-country-cultural

In the designated context, productively apply the concept "framing" entered into psychological use by E. Goffman. The general characteristic of the cultural framing as caused accepted in concrete community language, values, norms, schemes, values, concepts, physical artefacts, cultural activity and psychological phenomena sociocultural-interdeterminist dialogical structure setting an originality of the relation, experience and event interpretation, was represented in a number of the accented publications [32] [37].

Comprehension cultural framingness of consciousness caused by distinctions in epistemes, language, structure of values and norms, repertoire of activities does actual a problem of cultural competence. The construct "cultural competence" represents possession interacting parties learned configuration of categories, images, assumptions, beliefs, values, norms, and other symbolic elements widely shared among members of a given society or social group which functions as an orientational and normative framework for behavior, and as a communicational matrix through which behavior is interpreted, integrated, coordinated, and sanctioned, and as repertoire of the activity allowing effectively to realise in practice actual behavioral problems. Introduction of the given construct in the scientific conceptual device is caused by that in foreign tradition it used mainly for the description of possession by the maintenance of other culture [38] [39]. We focus attention on aspect of possession of the maintenance of own culture defining an originality self- and understanding the world and efficiency of its actualisation in interaction with a social and natural environment.

Cultural competence in the conditions of sharp strengthening of migratory streams starts to take on special significance in connection with competence intercultural. Moreover, the diffusive processes reflected in the content and an originality of own culture increase in the modern world. The parity of cultural and intercultural competence became a subject of our special analysis presented in accented article [40].

Developing dimensions of cultural competence and corresponding comprehension of existing objective distinctions in conditions (natural and social) acquirement with cultural wealth is necessary for the competence. Attempts of working out of such dimensions intensively develop foreign researchers, besides, with reference to an estimation of possession of another's culture [38] [39] [41] [42]. So Sue [39] in the review of researches of components of cultural competence allocates the following from them: cultural sensitivity in the form of perceptual schemes, knowledge of culture and cultural differences, awareness of one's own cultural assumptions, skills necessary for successful cultural, levels of worldviews, universal healing conditions moderated by culture-specific, the inclusive or exclusive nature of multiculturalism, and/or some combination of these factors. Helms and Richardson [43] are allocating three categories of cultural competence: (a) attitudes/beliefs component—an understanding of one's own cultural conditioning that affects personal beliefs, values, and attitudes; (b) knowledge component-understanding and knowledge of the worldviews of culturally different individuals and groups; and (c) skills component—use of culturally appropriate intervention/communication skills.

It is especially obvious on an example of cultural variety existing in the world collision with which occurs and in formation in connection with occurrence of foreign students, the professorates, showing evident samples of manifestation of emic (unique differences from all other cultures) and ethics (the general for all cultures). These cultural distinctions are boldly shown in dimensions of culture: psychobehavioural modalities, axiology (values), an etos (directing representations), epistemology (based on what we come to knowledge), logic (knowledge deducing) ontology (the reality nature), the concept of time and Self-concept [15]. 
Familiarity with variety of the given dimensions manifestations in various cultures promotes overcoming of ethnocentric tendencies in cultural development as a whole and education in particular. Ethnocentrism represents a universal tendency to consideration of the world and the decisions accepted by representatives of other cultures, proceeding from own cultural prospect. It explicitly or implicitly contains the idea that the proper culture is an important and superior compared to other groups [44].

Overcoming of costs of ethnocentrism is promoted by intercultural competence-ability to recognise, respect, value and use productively —in oneself and others—cultural conditions and determinants in perceiving, judging, feeling and acting with the aim of creating mutual adaptation, tolerance of incompatibilities and a development towards synergistic forms of cooperation, living together and effective orientation patterns with respect to interpreting and shaping the world [45]. It promotes movement prevailing in the modern world from ethnocentrism to ethnorelativism evolving requirements, making other demands to development of educational interaction both at level intercultural and monoculture concentrating on search of productive conditions and technologies for intercultural dialogue. The prerequisites and condition of intercultural competence is intercultural communicative competence-ability to negotiate cultural meanings and to execute appropriately effective communication behaviors that recognise the interactants' multiple identities in a specific environment [46]. This definition emphasizes that competent persons must know not only how to interact effectively and appropriately with people and environment, but also how to fulfil their own communication goals by respecting and affirming the multilevel cultural identities of those with whom they interact. Intercultural competence is inseparably interconnected with transcultural competence refers to an integrative theory-practice approach enabling us to mindfully apply the intercultural knowledge we have learned in a sensitive manner. Specifically, it refers to a transformation process connecting intercultural knowledge with competent practice [47].

Formation of these competences assumes presence of the corresponding supporting social environment. For a designation of this environment, the construct "eco-cultural dialogical educational environment" [40] has been introduced and a number of its formation conditions were allocated:

- construction of the general cultural semiotics space which are based on intersubjectivity (joint production of meanings) and intertextuality (coherence of the text with other texts);

- presence of a productive network of the dialogical (partner) communications assuming radical development of systems of feedback between all interested parties;

- creation of the information environment of mutually enriched type by means of informing and providing expert evaluations of a current state in the world educational space, achievements in the field of the theory and practice and tools and criteria's of independent search and accessible information resources estimation;

- contribution to development of pluralism and the tolerance, through acceptance of the alternative approaches possibility and supplying the bases and criteria of independent positioning in them;

- providing for interacting possibilities of self-finding in existing educational practices richness through testing of own features, "fittings" to itself of various ideas, approaches, educational technologies and their "agents" for the purpose of the optimal choice [40].

Incorporation in consideration of a problem of cultural and intercultural competence with inevitability assumes reconsideration of the substantial characteristic of the person traditionally considered through the description of the Self-concept content. Its consideration in a context of the concept "Self" in its Jams understanding as sets of all inherent for it is more perspective. This treatment assumes an exit for limits of the subject private world representations through connection of resources of interdeterminating interaction with Ego-extension including influence social and environment, individual life history, living society, direct and mediated social environment, etc. Such expansion is caused by comprehension of psychological underlying reason of the subject activity understanding possibilities limitation through results of informants questioning and self-reports which are only partly conscioused and often put questions before them owing to exhaustive answers absence. Moreover, reaction is often set by situational context originality, concrete person life history and its social environment, mediating translation of meanings, values and norms, the means of activity actualized in direct behaviour. Self is not for the last time given invariable structure, to identify which are mainly aimed traditional empirical studies. She is dynamical also multivoices, is multipositioning that visually shows dialogical Self approach Hermans [48] [49]. She is spatially structured and embodied, occupied by voices of other people, decentralized with widely open borders, historically and is cultural contextualized, possesses plurality of I-positions [49], interdeterminated, existential and dialogically integrated [7]. Innovationality of the given approach consists in introduction of the new positions joining in the Self-organisation; positions movement in the Self-space from a core to peri- 
phery and, on the contrary, by means of new cultural metaphors use; the cooperation of various positions leading to reorganization of system of Self.

The presented context of the sociocultural-interdeterminist dialogisity assumes revision of the interpersonal interaction problem, traditionally considered without the context of dialogue. Interpersonal interaction starts to be considered as process of mutually developed meanings and senses, values and norms, empathy, formation and development defining interacting subjects' mutual understanding. Removal on the foreground of a problem of interpersonal mutual understanding and event experience puts a problem of their tool "grasping" complicated by traditional static character of classical research toolkit. Inherent in interpersonal mutual understanding mediated sign character faces with the problem of interpretation and of the received sign content experience authenticity. The sign behind which stays concrete subjects life history, cultural competence, experience of the vital experiences accessible to him, but not transmitted in the communicated sign in essence representing only top of an iceberg of individual experience. From here the problem of the intertextuality focusing attention on the given text coherence with other texts, an ignorance with which leads to communicated meanings misunderstanding. Problem of hypertextuality, characterized by the presence of well known for the culture and subcultures represented in it texts, determining mutual understanding authenticity. Finally, the problem of intersubjectivity that characterizes synergy of dialogically co-concordant meanings creating mutual understanding foundation and its development in endless prospects. Being agreed on the stage of mutual familiarizing, shared meanings are creating foundation for subsequent reciprocal growth and mutual definiteness in its endless development. From here renewal of interest to dialogue in its Bachtinian understanding, increase of interest to dialogical research methodologies, etc. Bakhtin argued that dialogical relations "'must cloth themselves in discourse, become utterances, become the positions of various subjects expressed in discourse, in order that dialogic relationships might arise among them'" [50]. It is likely that this point meant that dialogue involves the engagement of people from different language communities when they engage in conversational rejoinders. Conversational rejoinders are the site of expression where socially constituted embodied experience comes into relation with another. The polyphonic condition of society makes dialogue so conceived unavoidable.

In discussing context of intercultural mutual understanding especially interesting are two propositions on globalization, proposed by Tu [51]. First, globalization can be hegemonic homogenization without cultural diversity and sensitivity, but through dialogue, it may lead to a genuine sense of global community. Second, the search for identity can degenerate into extreme ethnocentrism and exclusion, but through dialogue it may lead to an authentic way of intercultural communication and to a real respect for diversity. It is then up to us whether we will further risk our lifeboat by imposing the ethnocentric version of humanity on others and dividing the world with the clash of ignorance, or we will engage in mutual dialogue with the principle of "multiculturalism without hierarchy" toward "harmony without uniformity."

The presented sociocultural-interdeterminist dialogical prospect for problem of social and educational psychology development consideration, articulating an author's sight and theoretical baggage, it is initially focused on the constructive discussion directed on a finding of those agreed ways of vision and directions of researches, possessing in heuristic potential

\section{Conclusion}

Summarizing, once again, I focus attention to necessity of problems of social and educational psychology development horizons expansion, by means of: 1) multyparadigmality and multidisciplinarity applying resources accumulated in the related systems of paradigm coordinates and knowledge areas via the mechanism of interparadigm dialog; 2)comprehension of interdeterminatedness and reciprocity of personal, situational-contextual and activities components of interpersonal interactionand necessity of their interference detailed research; 3) psychological knowledge culturalisations by means of conceptual apparatus of modern cultural psychology, applying, ideas of interpersonal interaction subjects cultural cognitive activity framingness, incorporation questions of cultural and intercultural competence; 4) outgoing from frameworks of personocentrism by means of incorporation in analysis area of ego-extensions interdeterminating influence, including the social and natural environment placed in a concrete historical-cultural context; 5) considerations of interpersonal interaction as processual and dynamic phenomenon, presuming shared meanings fields and experiences formation mutually constructed and changed on the extension of mutual relations and living history; 6) designating of meanings and experiences sharedness as the intercultural interaction phenomenon's analysisunit using dialogical research methods and 
methodologies. The culture is not transmitted in itself, and shows soil of development, which will bear grateful growth under condition of the active and elaborated participation of all concerned participants. The cultural heritage content should be internalized in the most productive way with participation of all interested participants, that in the subsequent to be transformed to the cultural and intercultural competence, intending their optimum actualization in interaction of the person, subcultural groups and communities within social and natural environment, forming that eco-cultural and developing environment, promoting of mankind progressive and humanitarian development.

The author initially occupies tolerant, dialogical constructive criticism of the stated ideas and evaluative decisions, which it is possible to direct to the E-mail: yanchuk1303@gmail.com.

\section{References}

[1] Yanchuk, V.A. (2000) Methodology, Theory, and Methods in Modern Social Psychology and Personology: An Integrative-Eclectical Approach. Bestprint, Minsk. (Russian)

[2] Yanchuk, V.A. (2006) Postmodernist, Sociocultural-Interdeterminist Dialogisity as a Prospect of Positioning in Psychology Subject Methodology and History of Psychology, 1, 193-206. (Russian)

[3] Yanchuk, V.A. (2007) Postmodernist, Sociocultural-Interdeterminist Dialogical Prospect of Explanation in Psychology Methodology and History of Psychology, 2, 207-226. (Russian)

[4] Yanchuk, V.A. (2009) Progress in Psychological Phenomenology Understanding: Sociocultural-Interdeterminist Dialogical Prospect. In: Zguravlev, A.L., Marzinkovskaya, T.L. and Yurevich, A.V., Eds., Progress in Psychology: Criteria and Indicators, Institute of Psychology RAS, Moscow, 262-285. (Russian)

[5] Yanchar, S.C. and Slife, B.D. (2000) Putting It All Together: Toward a Hermeneutic Unity of Psychology. Journal of Mind and Behavior, 21, 325-326.

[6] Goertzen, J.R. (2010) Dialectical Pluralism: A Theoretical Conceptualization of Pluralism in Psychology. New Ideas in Psychology, 28, 201-209. http://dx.doi.org/10.1016/j.newideapsych.2009.09.013

[7] Yanchuk, V.A. (2005) Introduction to Modern Social Psychology. ASAR, Minsk, 768 p. (Russian)

[8] Healy, P. (2012) Toward an Integrative, Pluralistic Psychology: On the Hermeneutico-Dialogical Conditions of the Possibility for Overcoming Fragmentation. New Ideas in Psychology, 30, 271-280. http://dx.doi.org/10.1016/j.newideapsych.2011.12.005

[9] Smythe, W.E. and McKenzie, S.A. (2010) A Vision of Dialogical Pluralism in Psychology. New Ideas in Psychology, 28, 227-234. http://dx.doi.org/10.1016/j.newideapsych.2009.09.016

[10] Teo, T. (2010) Ontology and Scientific Explanation: Pluralism as an a Priori Condition of Psychology New Ideas in Psychology, 28, 235-243. http://dx.doi.org/10.1016/j.newideapsych.2009.09.017

[11] Valsiner Y. (2007) Becoming Integrative in Science: Re-building Contemporary Psychology through Interdisciplinary and International Collaboration. Integrative Psychological and Behavioral Science, 41, 1-5. http://dx.doi.org/10.1007/s12124-007-9002-2

[12] Ishii, S. (1997) Tasks for Intercultural Communication Researchers in the Asia-Pacific Region in the 21st Century. Dokkyo International Review, 10, 313-326.

[13] Samovar, L.A., Porter, R.E. and McDaniel, E.R. (2010) Communication between Cultures. 7th Edition, Wadsworth Cengage Learning, Boston, MA.

[14] Samovar, L.A., Porter, R.E. and McDaniel, E.R. (2010) Communication between Cultures. 7th Edition, Wadsworth Cengage Learning, Boston, MA, 150.

[15] Samovar, L. A., Porter, R. E. and McDaniel, E. R. (2012) Intercultural Communication: A Reader. 13th Edition, Wadsworth Cengage Learning, Boston, MA, 67.

[16] Jahoda, G. (2013) Critical Reflections on Some Recent Definitions of “Culture”. Culture \& Psychology, 18, $289-303$. http://dx.doi.org/10.1177/1354067X12446229

[17] Kroeber, A.L. and Kluckhohn, C. (1952) Culture: A Critical Review of Concepts and Definitions. Peabody Museum, Cambridge, MA.

[18] Kroeber, A.L. and Kluckhohn, C. (1952) Culture: A Critical Review of Concepts and Definitions. Peabody Museum, Cambridge, MA, 181.

[19] Hong, Y. (2009) A Dynamic Constructivist Approach to Culture: Moving from Describing Culture to Explaining Culture. In: Wyer, R.S., Chiu, C.-Y. and Hong, Y.-Y., Eds., Understanding Culture: Theory, Research and Application (pp. 3-23). Psychology Press, New York. 
[20] Wan, C. and Chiu, C. (2009). An Intersubjective Consensus Approach to Culture. The Role of Intersubjective Norms versus Cultural Self in Cultural Processes. In Wyer, R.S., Chiu, C.-Y. and Hong, Y.-Y., Eds., Understanding Culture: Theory, Research and Application, Psychology Press, New York, 80, 79-91.

[21] Ishii, S. (1997) Tasks for Intercultural Communication Researchers in the Asia-Pacific Region in the 21st Century. Dokkyo International Review, 10, 313-326.

[22] Ishii, S. (1997) Tasks for Intercultural Communication Researchers in the Asia-Pacific Region in the 21st Century. Dokkyo International Review, 10, 313-326, 321.

[23] Yanchuk V.A. (2000) Methodology, Theory, and Methods in Modern Social Psychology and Personology: An Integrative-Eclectical Approach. Bestprint, Minsk, 11.

[24] Yanchuk, V.A. (2006) Postmodernist, Sociocultural-Interdeterminist Dialogisity as a Prospect of Positioning in Psychology Subject. Methodology and History of Psychology, 1, 204. (Russian)

[25] Ranganath, K.A., Spellman, B.A. and Joy-Gaba, J.A. (2010) Cognitive “Category-Based Induction” Research and Social "Persuasion” Research Are Each about What Makes Arguments Believable: A Tale of Two Literatures. Perspectives on Psychological Science, 5, 115-122. http://dx.doi.org/10.1177/1745691610361604

[26] Meiser, T. (2011) Much Pain, Little Gain? Paradigm-Specific Models and Methods in Experimental Psychology. Perspectives on Psychological Science, 6, 183-184. http://dx.doi.org/10.1177/1745691611400241

[27] Healy, P. (2012) Toward an integrative, Pluralistic Psychology: On the Hermeneutico-Dialogical Conditions of the Possibility for Overcoming Fragmentation New Ideas in Psychology, 30, 275-278. http://dx.doi.org/10.1016/j.newideapsych.2011.12.005

[28] Sternberg, R.J. and Grigorenko, E.L. (2001) Unified Psychology. American Psychologist, 56, 1069-1079. http://dx.doi.org/10.1037/0003-066X.56.12.1069

[29] Nilsson A. (2014) Personality Psychology as the Integrative Study of Traits and Worldviews. New ideas in Psychology, 32, 29.

[30] Bandura, A. (1986) Social Foundation of Thought and Action: A Social Cognitive Theory. Prentice Hall, Englewood Cliffs, NJ.

[31] Franklin, C.W. (1982) Theoretical Perspectives in Social Psychology. Little, Brown and Company, Boston.

[32] Yanchuk, V.A. (2010) Cultural Framing as Determinant of Mutual Understanding in the Conditions of Cultural Diversity. Psychological Journal, 2, 41-48. (Russian)

[33] Foucault, M. (1972) The Archaeology of Knowledge and the Discourse on Language. Pantheon Books, New York.

[34] Bukobza, G. (2007) The Epistemological Basis of Selfhood. New Ideas in Psychology, 25, 37-65. http://dx.doi.org/10.1016/j.newideapsych.2006.11.001

[35] Foucault, M. (1972) The Archaeology of Knowledge and the Discourse on Language. Pantheon Books, New York, xiv.

[36] Pepper, S.C. (1942) World Hypotheses: A Study in Evidence. University of California Press, Berkeley.

[37] Yanchuk, V.A. (2014) The Methodological, Theoretical and Empirical Problems of the Unclosely and Closely-Related Cultures and Ethnosis Research. In: Gritsenko, V., Ed., Theoretical Problems of Ethnic and Cross-Cultural Psychology: Materials of 4-th International Conference, May 30-31, 2014, Smolensk: Smolensk Humanitarian University, Vol. 1, 15-23. (Russian)

[38] Bustamante, R.M., Nelson, J.A. and Onwuegbuzie, A.J. (2009) Assessing Schoolwide. Cultural Competence: Implications for School Leadership Preparation Educational Administration Quarterly, 45, 793-827.

[39] Sue, D.W. (2001) Multidimensional Facets of Cultural Competence The Counseling Psychologist, 29, 790-821.

[40] Yanchuk, V.A. (2013) Eco-Cultural Educational Environment: Formation and Development. Part 2: From Cultural to the Intercultural Competence. Education and Nurture, 1, 69-76. (Russian)

[41] Bustamante, R.M., Nelson, J.A. and Onwuegbuzie, A.J. (2009) Assessing Schoolwide. Cultural Competence: Implications for School Leadership Preparation. Educational Administration Quarterly, 45, 793-827.

[42] Smith, P.B., Peterson, M.F., Thomason, S.J., Yanchuk, V.A., et al. (2011) National Culture as a Moderator of the Relationship Between Managers' Use of Guidance Sources and How Well Work Events Are Handled. Journal of CrossCultural Psychology, 42, 1101-1121. http://dx.doi.org/10.1177/0022022110381427

[43] Smith, P.B., Torres, C.V., Yanchuk, V.A., et al. (2011) Individualism-Collectivism and Business Context as Predictors of Behaviors in Cross-National Work Settings: Incidence and Outcomes. International Journal of Intercultural Relations, 35, 440-451. http://dx.doi.org/10.1016/j.ijintrel.2011.02.001

[44] Matsumoto, D. (2009) The Cambridge Dictionary of Psychology. David Matsumoto (General ed.), Cambridge University Press, 61. 
[45] Spencer-Oatey, H. and Franklin, P. (2009) Intercultural Interaction: A Multidisciplinary Approach to Intercultural Communication. Palgrave Macmillan. http://dx.doi.org/10.1057/9780230244511

[46] Chen, G.-M. and Starosta, W.J. (1996) Intercultural Communication Competence: A Synthesis. Communication Yearbook, 19, 353-384.

[47] Ting-Toomey, S. (1999) Communicating across Cultures. The Guilford Press, New York, 261.

[48] Hermans, H.J.M. and Kempen, H.J. (1993) The Dialogical Self. Academic Press, London.

[49] Hermans, H.J.M. (2002) The Dialogical Self as a Society of Mind: Introduction. Theory \& Psychology, 12, $147-160$. http://dx.doi.org/10.1177/0959354302122001

[50] Bakhtin, M.M. (1984) Problems of Dostoevsky’s Poetics. University of Minnesota Press, Minneapolis, MN, 183.

[51] Tu, W. (2001) The Context of Dialogue: Globalization and Diversity. In: Picco, G., Ed., Crossing the Divide: Dialogue among Civilizations, School of Diplomacy and International Relations, Seton Hall University, South Orange, NJ, 4996. 